\title{
SILICOSIS IN SWITZERLAND
}

\section{MICHAEL F. KOLLER ${ }^{1}$, STEFAN M. SCHOLZ ${ }^{2}$, CLAUDIA PLETSCHER ${ }^{1}$, and DAVID MIEDINGER ${ }^{1}$}

\author{
Suva, Lucerne, Switzerland \\ ${ }^{1}$ Division of Occupational Medicine \\ ${ }^{2}$ Department of Statistics
}

\begin{abstract}
Objectives: The correlation between quartz dust concentrations in the Swiss enterprises and the incidence of silicosis and other related diseases acknowledged as occupational diseases (OD) was investigated. Material and Methods: Quartz dust concentrations were obtained from Suva's databases of occupational health surveillance measurements between 2005 and 2014. Information on quartz dust-related diseases was from medical dossiers of workers with OD acknowledged by Suva between 2005 and 2014. Results: The median quartz dust concentration of the 2579 measurements between 2005 and 2014 was $0.09 \mathrm{mg} / \mathrm{m}^{3}$ (alveolar fraction). Out of all measurements, 28\% were above the Swiss occupational exposure limit (OEL) of $0.15 \mathrm{mg} / \mathrm{m}^{3}$ (alveolar fraction). One hundred eighty-one individuals suffered from acknowledged quartz dust-related disease (179 silicosis and 2 chronic obstructive pulmonary disease (COPD)). Additionally, 8 out of these workers were diagnosed with lung cancer and 55 with COPD of a non-specified cause. Out of all workers, $46 \%$ were exposed to silica dust for the first time before 1975 when the current Swiss OEL was introduced. Out of the foreign workers, $63 \%$ began to work abroad, during which they could have at least partly acquired their silicosis. Out of all workers, $75 \%$ were ever-smokers. Conclusions: The incidence of silicosis decreased drastically from approximately 300 cases/year in the 1970s to fewer than 20 cases/year 20 years ago. Several findings of this study that could help to interpret the ongoing occurrence of the disease include excessive exposure in or outside of Switzerland in former or current times, vulnerability to the development of silicosis due to cigarette smoke, or poor compliance with wearing breathing masks. Int J Occup Med Environ Health 2018;31(5):659-676
\end{abstract}

Key words:

Lung cancer, Silicosis, Quartz, Occupational exposure limit, Crystalline silica, Switzerland

\section{INTRODUCTION}

Several occupational exposure limit (OEL) committees are or have been recently reevaluating the OEL for crystalline silica. In this context, we have reviewed the quartz dust concentrations recorded in Suva's database of workplace air-monitoring campaigns as well as medical records of individuals with quartz dust-related diseases recognized by Suva as an occupational disease. We wanted to investigate the current state of silica dust exposure in the workplace and its association with the frequency of different silica-related occupational diseases (OD).
Silica (silicon dioxide $-\mathrm{SiO}_{2}$ ) is the anhydride of silicic acid $\left(\mathrm{Si}(\mathrm{OH})_{4}\right)$ and belongs to the large group of silicates. There are both crystalline and amorphous modifications of silica. The latter ones are found in various rocks, radiolaria, diatoms, sponges, and kieselguhr, among others, whereas crystalline forms occur only in rocks. The most important crystalline modification is quartz which is the second most common mineral in the earth crust (after silicate feldspar). Other modifications of crystalline silica, such as cristobalite and tridymite, are considerably more rare. Therefore, in practice, the term "quartz" is often used simplistically for crystalline $\mathrm{SiO}_{2}$. Since quartz

Received: September 25, 2017. Accepted: December 22, 2017.

Corresponding author: Michael F. Koller, Suva, Division of Occupational Medicine, Fluhmattstrasse 1, CH-6002 Lucerne, Switzerland (e-mail: michael.koller@suva.ch). 
occurs in most kinds of rocks, numerous activities are associated with exposure to quartz, like tunnel construction, quarries, gravel, stone processing, furnace construction, the ceramic, glass and building materials industries, foundries, the demolition of concrete structures and sandblasting or grinding through the use of quartz.

Crystalline silica dust may lead to several diseases when inhaled repeatedly. The respirable fraction of the dust deposits in the bronchi and alveoli lead to chronic inflammation and subsequently silicosis, lung cancer, chronic bronchitis or chronic obstructive pulmonary disease (COPD). Other diseases that are related to silica are tuberculosis, pleural plaques, scleroderma, rheumatoid arthritis or chronic kidney diseases [1].

The most important occupational disease in context with silica is silicosis. Suva (Schweizerische Unfallversicherungsanstalt - the Swiss National Accident Insurance Fund) has recognized silicosis as a quartz dust-related occupational disease since 1938.

Silicosis is a pneumoconiosis that is a lung fibrosis caused by inorganic dust. The fibrogenic potential of silica depends on its modification, e.g., tridymite is more fibrogenic than cristobalite, which is more fibrogenic than quartz [1]. The most critical factor for the development of silicosis is the accumulated amount of crystalline $\mathrm{SiO}_{2}$ [1].

Typically, approximately 10-20 years of exposure [2] are required until enough dust has been accumulated to lead to silicosis with obstructive and restrictive ventilation alterations and various symptoms, such as dyspnea or cough. In exceptional cases, silicosis develops after as little as 5-10 years (accelerated silicosis), or even faster after weeks to years following very high silica concentrations (acute silicosis or silicoproteinosis) [1]. During the latency period, most patients do not report any respiratory symptoms. Silicosis may progress even in the absence of additional ongoing exposure. The disease is irreversible, and only supportive care may be offered.
The diagnosis and determination of severity of silicosis is performed with the help of the medical history, clinical examination, such as lung function, X-ray or high-resolution computer tomography (HRCT) of the chest, and lung biopsy for the detection of granuloma and birefringent crystals. A pneumoconiosis seen on the radiograph image is graded using the reference set out by the International Labor Office (ILO) [3].

Crystalline silica was classified as a $\mathrm{Cl}_{\mathrm{A}}$ carcinogen by Suva in 2011 [4]. The exposure time needed to develop lung cancer requires many years, with reports of approximately 15 years [1]. The carcinogenic power of crystalline silica is weak, and the correlation curve between the accumulated amount of quartz dust and the risk of lung cancer is flat $[1,5,6]$. The risk differs depending on the type of crystalline $\mathrm{SiO}_{2}$, the particle surface, and the co-occurrence of other carcinogenic substances, among others. The mechanisms involved in carcinogenesis are chronic inflammation or - probably at higher concentrations the production of reactive oxygen species (ROS) [5,7]. As chronic inflammation is a non-genotoxic mechanism, the existence of a threshold value regarding carcinogenesis is discussed [8-11]. Other discussions concern the question if silicosis is a requirement for the development of lung cancer $[12,13]$ because lung cancer is mainly seen in the case of workers with silicosis. Suva recognizes lung cancer as a silica dust-related disease only in the presence of a co-existing silicosis.

The third important lung disease related to crystalline silica is COPD [14-16]. The risk of developing COPD depends on the accumulated dose of silica; however, the most important risk factor for COPD is tobacco smoke.

To protect workers from these lung diseases, many countries have introduced OELs. In Switzerland, Suva issues guidelines [4] on the maximum workplace concentrations of harmful substances (article 50.3, ordinance regulating accident prevention and occupational diseases), in agreement with the Committee on Occupational Exposure 
Limits of Suissepro (Swiss Association for Occupational Health, Occupational Hygiene and Safety). Suva introduced the first OEL for alveolar fraction of crystalline silica (a), of $0.3 \mathrm{mg} / \mathrm{m}^{3}$ in 1971 . The OEL was decreased in 1975 to the current value of $0.15 \mathrm{mg} / \mathrm{m}^{3}$ (a). To comply with the OEL, the number of technical and personal protective measures such as wet drilling, exhaust ventilation, closed systems or encapsulation, avoidance of sandblasting, and wearing a breathing mask, among others, have to be used. Moreover, the most exposed workers are included in prophylactic occupational medical programs of Suva with periodic investigation by a physician (in 2015, there were approximately 10000 workers in such a program). When a worker develops a silicosis (or another disease), Suva may issue a declaration of unsuitability, which means that the concerned worker is no longer allowed to perform a job where he is exposed to quartz dust. Suva may optionally issue a declaration of conditional suitability, which means that the worker is only allowed to continue his occupation when he wears a breathing mask.

\section{MATERIAL AND METHODS}

\section{Data sources}

In Switzerland, Suva conducts workplace air measurements to verify compliance with the OEL of crystalline silica. The results are registered in an internal database. We analyzed the following data for measures generated during the period 2005-2014: quartz dust concentration, duration of measurement, type of measurement (stationary/personal), measuring strategy (time-weighted average, workplace-related, job-related), activity defined by the expert (stone processing, tunneling, graveling, foundry, ceramics, material production, food production and processing, renovation, recycling, preparing mixtures, processing plastics, nanotechnology, fiber processing, not determined).

In Switzerland, all occupational diseases recognized by an accident insurance company are registered by the
Swiss Central Office for Statistics in Accident Insurance (Sammelstelle für die Statistik der Unfallversicherung - SSUV). Lung cancer, COPD and other illnesses are in general only acknowledged as a quartz dust-related disease when there is co-existing silicosis. We analyzed all those cases where a silica dust-related disease has been recognized by Suva between 2005 and 2014. We extracted the diagnosis, year of birth, sex, year of registration, year of recognition, year of death (and a flag indicating if death was deemed to be due to silicosis), which had been acknowledged between 2005 and 2014.

From the cases extracted from the SSUV database, we consulted the medical files available at Suva and extracted the country of origin, smoking history (actual smoker, non-smoker, never-smoker, pack years), predilated lung function parameters of forced expiratory volume in one second $\left(\mathrm{FEV}_{1}\right)$, forced vital capacity $(\mathrm{FVC})$ and $\mathrm{FEV}_{1} / \mathrm{FVC}$ ratios, self-rated adequate personal protection over time (yes, no), declaration of unsuitability (yes, no), and whether the diagnosis was determined over the course of routine occupational medical prophylaxis exams (yes, no). The accumulated silica dose was recorded. ("Quartz years" - a "quartz year" is the accumulated silica dust over a working life given in $\mathrm{mg} / \mathrm{m}^{3} \times$ years. It is calculated by a Suva expert who estimates the average quartz dust concentration of each occupation in which a worker has worked, and sums all the time-weighted concentrations. The estimation of the quartz dust concentrations of each occupation is based on measurements, or when no measurements have been performed, on comparisons with similar companies with available data. Sometimes the expert calculates a minimum and a maximum amount. We conveniently took only the higher estimation for further analysis.). For the time courses, the year of start and year of finish of work in each activity with quartz exposure (both inside and outside of Switzerland) that were generally self-reported by the individual, year of registration and recognition of the occupational disease were obtained 
from the files; this data was usually self-reported by the patients. The number of years a worker had been employed in an activity was multiplied by the yearly employment rate to obtain the effective exposure time; in case the employment rate was not available in the insurance dossier, we instead assumed a value of $100 \%$.

\section{Statistical analysis}

The statistical analysis consisted of calculating the medians (Me), interquartile ranges (IQRs) and 90th percentiles/year. We did not determine the 90th percentiles when $\mathrm{N}<20$. We also determined the number of quartz dust concentrations that were higher than the OEL of Switzerland or other committees. To analyze temporal trends, we calculated linear regression for time series. The statistical significance of the data of subgroups compared to the remaining cases was analyzed by the Mann-Whitney $\mathrm{U}$ test for unpaired data (two-tailed).

\section{Ethical approval statement}

Ethical approval for this study was given by the Ethics Committee of Northwest and Central Switzerland (Ethikkommission Nordwest- und Zentralschweiz), application No. EKNZ 2016-00731.

\section{RESULTS}

\section{Exposure measurements}

There were 3707 single measurements registered in the Suva database between 2005 and 2014. The measurements were performed in 207 companies during one or several visits. The 2579 (70\%) measurements were further analyzed, and 1128 (30\%) measurements were discarded. The discarded measurements were as follows: 60 measurements with measurement times $<60 \mathrm{~min}$ (which are considered to be too short to be of relevance by Suva occupational hygienists), 2 failed measurements, 4 worst case measurements, 26 reference measurements, 8 orienting measurements, 674 emission source measurements and 354 back- ground room measurements. In 12 cases, the results were lower than the detection limit of $0.01 \mathrm{mg} / \mathrm{m}^{3}$ (a); in these cases, we used $0.0099 \mathrm{mg} / \mathrm{m}^{3}$ (a), which is a value that does not otherwise exist in the Suva database.

There were 252 measurements/year (median; IQR = 218-285) with a median measuring time of $181 \mathrm{~min}$ $(\mathrm{IQR}=138-350)$. The median alveolar silica dust concentration of all activities together and of the individual activities of stone processing, tunneling, foundry and ceramics were $0.08-0.09 \mathrm{mg} / \mathrm{m}^{3}$ (Table 1). There was no positive or negative trend with time for the total silica dust concentration $\left(\mathrm{R}^{2}\right.$ of the linear regression of the median concentrations per year $=0.02$ ). The mean concentrations were considerably higher than the median values (data not shown). Measurements were performed by applying either personal or stationary sampling methods. Measurements performed by personal sampling ( $\mathrm{N}=1347)$ yielded slightly, but significantly, higher median alveolar silica dust concentrations $\left(0.1 \mathrm{mg} / \mathrm{m}^{3}\right.$; IQR $\left.=0.05-0.21 \mathrm{mg} / \mathrm{m}^{3}\right)$ compared with the measurements performed by stationary sampling $\left(0.08 \mathrm{mg} / \mathrm{m}^{3} ; \mathrm{IQR}=0.04-0.14 \mathrm{mg} / \mathrm{m}^{3} ; \mathrm{N}=1231\right)$. Analogously, the concentrations of each individual activity were significantly higher for personal samplings than for stationary measurements except for graveling, for which the proportion was the opposite (data not shown).

The percentage of measurements that were higher than the Swiss OEL of $0.15 \mathrm{mg} / \mathrm{m}^{3}$ (a) was $28 \%$ (Table 2). The smallest ratio was observed in foundries, with only $17 \%$ exceeding the current Swiss OEL; the highest percentage was in gravel quarries, among which $54 \%$ had levels that were considered to be too high. If the OEL was $0.1 \mathrm{mg} / \mathrm{m}^{3}$ and $0.05 \mathrm{mg} / \mathrm{m}^{3}$ (a), as recommended by other OEL commissions, then $43 \%$ and $68 \%$ of all measurements would be too high.

The 3 analyzed measuring strategies were "workplacerelated," "job-related" and "time-weighted average" measurements. The median of all workplace-related measurements was $0.08 \mathrm{mg} / \mathrm{m}^{3}$ (a) (IQR $=0.03-0.14 ; \mathrm{N}=1140$; 
Table 1. Quartz dust concentrations in studied enterprises in Switzerland, 2005-2014, by activity

\begin{tabular}{lccccr}
\hline \multirow{2}{*}{\multicolumn{1}{c}{ Activity }} & Measurements & \multicolumn{3}{c}{$\begin{array}{c}\text { Alveolar quartz dust concentration } \\
{\left[\mathrm{mg} / \mathrm{m}^{3}\right]}\end{array}$} & $\mathrm{p}$ \\
\cline { 3 - 5 } & {$[\mathrm{n}]$} & $\mathrm{Me}$ & $\mathrm{IQR}$ & $90 \%$ percentile & \\
\hline Stone processing & 1072 & 0.08 & $0.04-0.16$ & 0.39 & $<0.01$ \\
Tunneling & 915 & 0.09 & $0.05-0.15$ & 0.27 & 0.09 \\
Graveling & 316 & 0.17 & $0.09-0.29$ & 0.48 & $<0.01$ \\
Foundry & 86 & 0.09 & $0.05-0.14$ & 0.24 & 0.92 \\
Ceramics & 17 & 0.09 & $0.02-0.12$ & n.d. & 0.34 \\
Other* & 173 & 0.05 & $0.02-0.11$ & 0.50 & $<0.01$ \\
Total & 2579 & 0.09 & $0.04-0.17$ & 0.36 & \\
\hline
\end{tabular}

Me - median; IQR - interquartile range; n.d. - not determined.

* Material production, food production, processing, recycling, preparing mixtures, processing plastics, nanotechnology, fiber processing, and not determined.

Table 2. Quartz dust concentrations in studied enterprises in Switzerland, 2005-2014, by concentration and activity

\begin{tabular}{lcccc}
\hline \multirow{2}{*}{ Activity } & Measurements & \multicolumn{3}{c}{$\begin{array}{c}\text { Alveolar quartz dust concentration } \\
{[\%]}\end{array}$} \\
\cline { 3 - 5 } & {$[\mathrm{n}]$} & $>0.05 \mathrm{mg} / \mathrm{m}^{3}$ & $>0.1 \mathrm{mg} / \mathrm{m}^{3}$ & $>0.15 \mathrm{mg} / \mathrm{m}^{3}$ \\
\hline Stone processing & 1072 & 65 & 39 & 26 \\
Tunneling & 915 & 69 & 41 & 24 \\
Graveling & 316 & 87 & 69 & 54 \\
Foundry & 86 & 74 & 41 & 17 \\
Ceramics & 17 & 69 & 44 & 19 \\
Other* & 173 & 48 & 27 & 21 \\
Total & 2579 & 68 & 43 & 28 \\
\hline
\end{tabular}

Explanations as in Table 1.

$p<0.001$ ), the time-weighted average measurements yielded a median of $0.1 \mathrm{mg} / \mathrm{m}^{3}$ (a) $(\mathrm{IQR}=0.05-0.22 ; \mathrm{N}=1236$; $\mathrm{p}<0.001)$ and the median of job-related measurements was $0.08 \mathrm{mg} / \mathrm{m}^{3}$ (a) $(\mathrm{IQR}=0.04-0.16 ; \mathrm{N}=203 ; \mathrm{p}=0.09)$.

\section{Quartz dust-related diseases}

One hundred seventy-nine cases of silicosis (including mixed pneumoconiosis) and two cases of quartz dust-related COPD (without coexisting silicosis) were acknowledged as quartz dust-related diseases by Suva between 2005 and 2014 (COPD is only recognized as a quartz dust-related disease by Suva when there is a coexisting silicosis, which was, exceptionally, not the case in these two COPD cases). One hundred eighty diseases were diagnosed in the case of men, and one case of silicosis occurred in the case of a woman. The median number of diseases recognized per year was 19 (IQR $=15-21$ ). There was no clear timely increase or decrease in incidence $\left(\mathrm{R}^{2}\right.$ of the linear regression of the yearly median of diseases of 0.15$)$. 
The most common respiratory diseases diagnosed in addition to silicosis were quartz dust-related lung cancer $(\mathrm{N}=8)$ and COPD of unspecified cause $(\mathrm{N}=55)$. These lung cancers were recognized as silica dust-related disease by Suva because silicosis with an ILO grade of at least $1 / 1$ was also present. In the case of COPD, there are usually no statements on causality in the medical files. Further secondary diagnosis such as e.g., tuberculosis is not provided herein.

In 2005-2014, 19 (10\%) workers died of silica dust-related diseases (silicosis: $\mathrm{N}=14$, and lung cancer: $\mathrm{N}=5$ ).

Twenty-six (14\%) of the workers received a declaration of unsuitability, and $21(12 \%)$ workers received a conditional declaration of unsuitability (which means that they could continue with their activity when wearing a breathing mask). Additional 11 workers changed their activity due to silicosis without a declaration of unsuitability (which corresponds to $7 \%$ of the 152 workers for whom medical follow-up was available); this figure must be considered with caution because there a complete follow-up was typically not performed. The workers who did not have to quit their job either continued their original work, retired or they had already changed their original activity at a prior time. We analyzed the predilated lung function parameters $\left(\mathrm{FEV}_{1}, \mathrm{FVC}\right.$ and $\mathrm{FEV}_{1} / \mathrm{FVC}$ ratios) for those workers, in the case of whom silicosis had been recognized after 2010, and in the case of whom lung function parameters were available in the insurance dossiers $(\mathrm{N}=69$ for $\mathrm{FEV}_{1}, \mathrm{~N}=68$ for $\mathrm{FVC}$ and $\mathrm{N}=67$ for $\mathrm{FEV}_{1} / \mathrm{FVC}$ ). The median $\mathrm{FEV}_{1}$ was $86 \%$ of the predicted value (IQR $=75-103 \%)$, and the median FVC was $92 \%$ of the predicted value (IQR $=83-105 \%)$, adjusted by age. The median of the $\mathrm{FEV}_{1} / \mathrm{FVC}$ ratios was 0.78 (IQR = 0.69-0.84). The workers without COPD showed a median $\mathrm{FEV}_{1} / \mathrm{FVC}$ ratio of 0.81 (IQR $=0.73-0.9 ; \mathrm{N}=46$ ) whereas the ratio was significantly lower for the workers with COPD: 0.68 (IQR $=0.56-0.73 ; \mathrm{N}=18$ ) $(\mathrm{p}<0.005)$.

\section{Origin of the workers}

The 3 most frequent countries of origin were Portugal, Switzerland and Italy, where 29\%, 27\% and 23\% $(\mathrm{N}=142)$, respectively, of all workers had been born. Among all the workers, $73 \%(\mathrm{~N}=133)$ had been born outside of Switzerland.

The percentage share of foreigners was the highest in construction (84\%). Eighty-five percent of all Portuguese workers were employed in stone processing whereas tunneling was performed by $39 \%$ of the Italians.

\section{Year of starting work}

The median year of the first occupational exposure towards quartz dust (Figure 1) was 1972 (IQR = 19591982; N = 179). The median year of birth (Figure 2) was 1953 (IQR = 1940-1961; N = 181), and the median age at the first occupational exposure to silica dust (Figure 3) was 18 years (IQR = 15-24 years; $\mathrm{N}=179$ ). The age of starting work was not correlated with the year of birth (R2 of the linear regression of 0.06 ) - this means that workers in former times did not start to work at a younger age as compared with more recent times.

There was no correlation between quartz years and the real total working time of each worker $\left(\mathrm{R}^{2}\right.$ of the linear regression of 0.002) or between the quartz years and the time between the start of work and recognition of disease $\left(\mathrm{R}^{2}\right.$ for the linear regression of 0.002 ).

Among all workers, $46 \%$ started to work in Switzerland before the Swiss OEL had been lowered to $0.15 \mathrm{mg} / \mathrm{m}^{3}$ (a) in 1975. Since 10-20 years of exposure to quartz dust are needed until silicosis develops [2], we also calculated the percentage of workers who started to work in Switzerland 10 and 20 years before the current Swiss OEL had been introduced: $30 \%$ and $9 \%$ of workers had started to work before 1965 and 1955, respectively. We do not know the details of the OELs in the countries of origin of the workers in this study. 


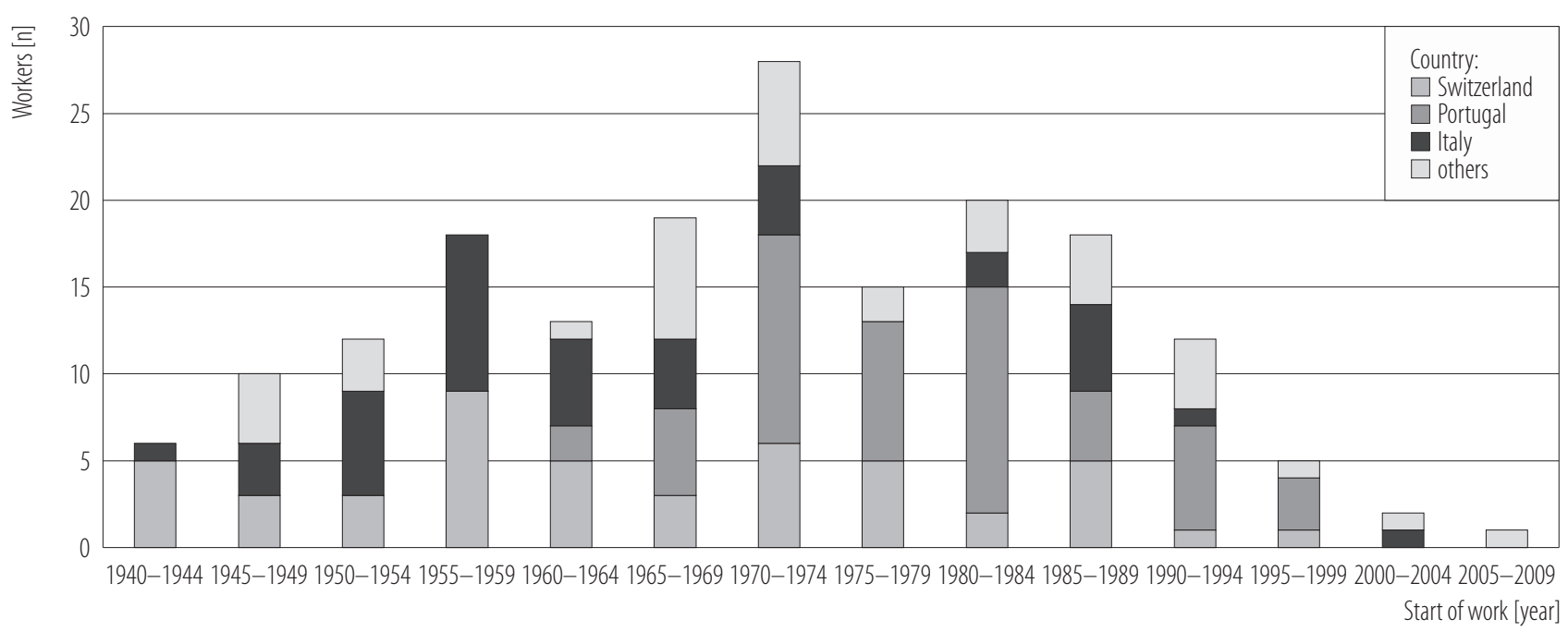

Three most frequent countries of birth are Portugal, Switzerland, and Italy.

Fig. 1. Year of first occupational exposure towards quartz dust of workers ( $\mathrm{N}=179)$ in studied enterprises in Switzerland, 2005-2014

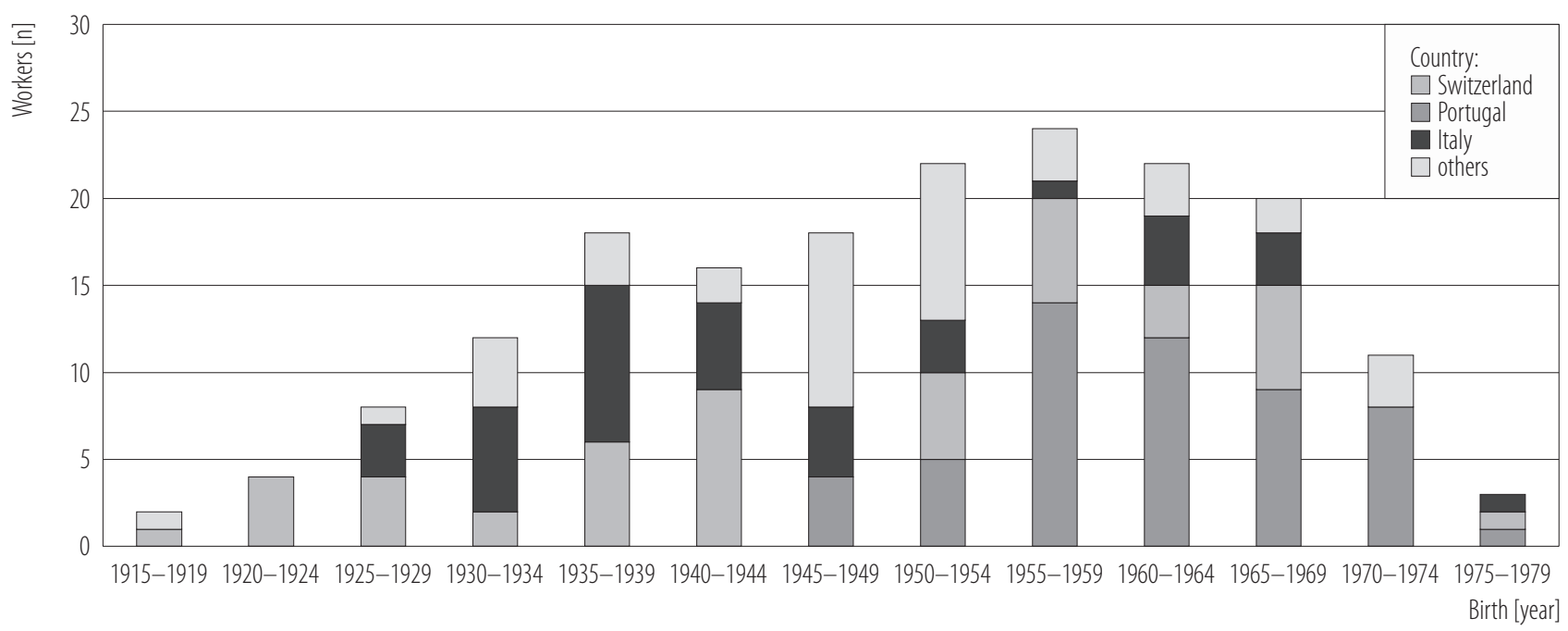

Explanation as in Figure 1.

Fig. 2. Years of birth of workers occupationally exposed towards silica dust $(\mathrm{N}=181)$ in studied enterprises in Switzerland, 2005-2014

\section{Time point of recognition of silicosis by Suva}

The median age at the time point of recognition of silicosis as an occupational disease by Suva was 58 years (IQR $=48$ 70 years; $\mathrm{N}=181$ ). The youngest worker was 34 years old, and the oldest was 90 years old (Figure 4). The year of acknowledgement was a median of 39 years $(\mathrm{IQR}=$
$27-50$ years) after the year of starting work. There was no significant time difference in the start of work and recognition between Swiss and Italian workers; however, the time difference between the start of work and recognition was 18 years (median) shorter for Portuguese workers due to the later immigration of this population into Switzerland (Figure 1). 


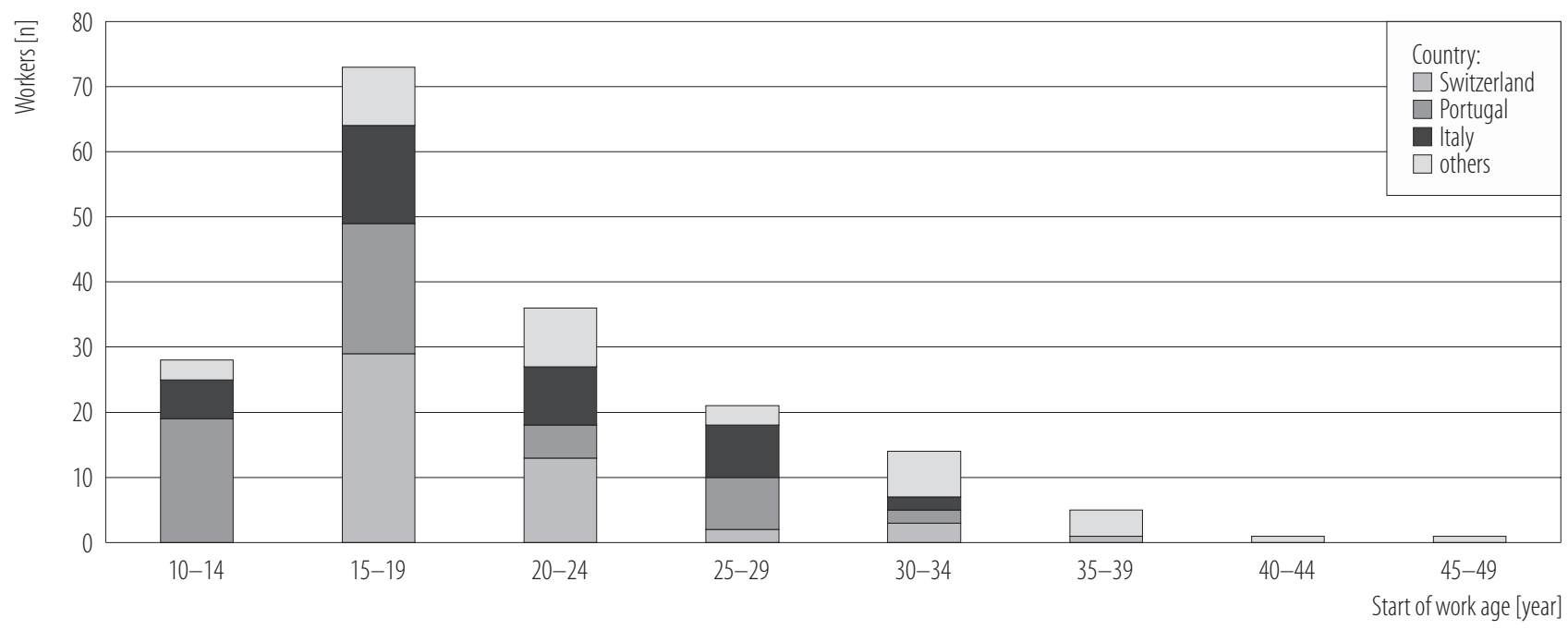

Explanation as in Figure 1.

Fig. 3. Median age at start of work with occupational silica dust exposure of workers $(\mathrm{N}=179)$ in studied enterprises in Switzerland, 2005-2014

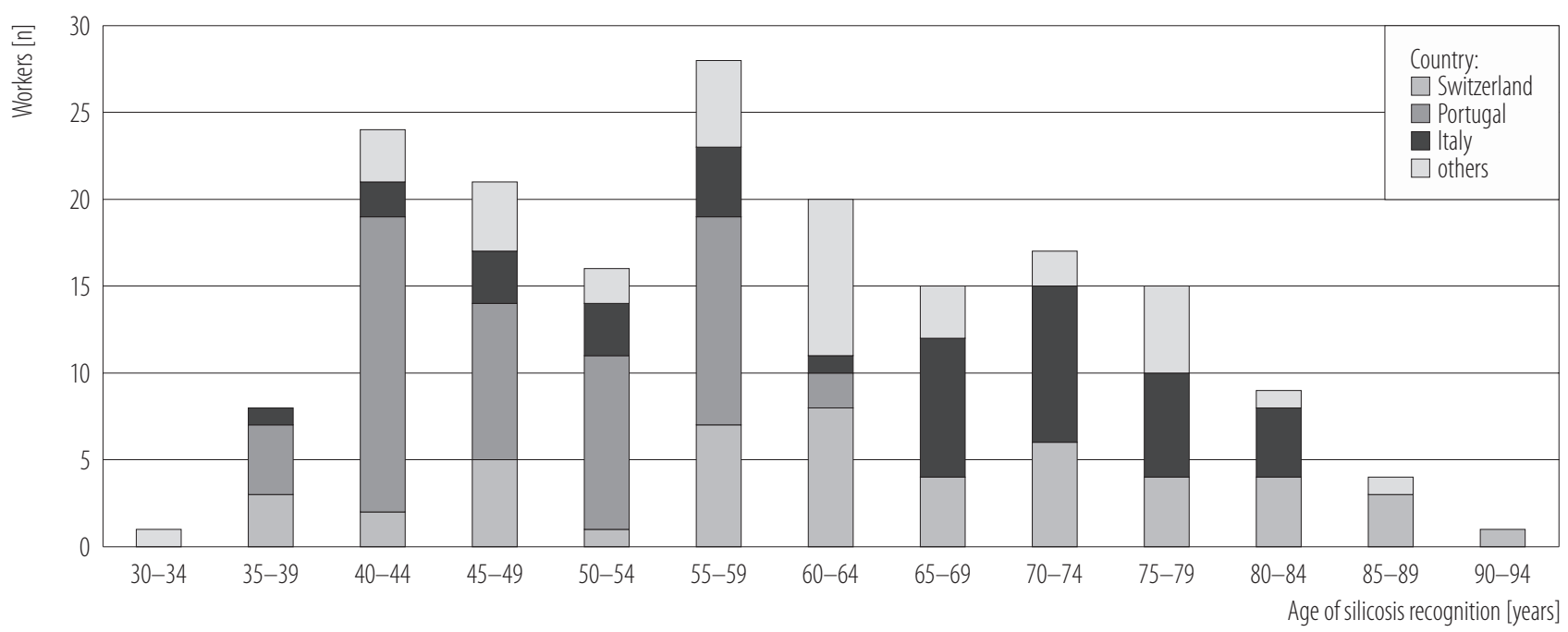

Suva - the Swiss National Accident Insurance Fund (Schweizerische Unfallversicherungsanstalt).

Other explanations as in Figure 1.

Fig. 4. Age at the time point of recognition of silicosis as occupational disease by Suva of workers in studied enterprises in Switzerland, 2005-2014

We attempted to analyze when a worker noticed symptoms for the first time or when a medical doctor first described diagnostic indices for silicosis. We found corresponding data for 163 medical dossiers. The median age when symptoms or diagnostic hints appeared was 54 years $(\mathrm{IQR}=43-63$ years), which was approximately 33 years (IQR = 23-43 years; median) after the year of starting work. As the workers did not always remember the exact time point of the start of symptoms and as it was not always clear if the described symptoms were 
Table 3. Time during which a worker performed an activity, according to the insurance dossiers ${ }^{1}$, in studied enterprises in Switzerland, 2005-2014

\begin{tabular}{lcc}
\hline \multicolumn{1}{c}{ Activity } & $\begin{array}{c}\text { Workers } \\
{[\mathrm{n}]}\end{array}$ & $\begin{array}{c}\text { Seniority }^{2} \\
\text { [years] } \\
\text { (Me (IQR)) }\end{array}$ \\
\hline Stone & 94 & $28(20-38)$ \\
Tunnel & 48 & $18(10-31)$ \\
Gravel & 9 & $10(8-24)$ \\
Foundry & 22 & $30(16-41)$ \\
Construction & 25 & $23(12-30)$ \\
Ceramics & 7 & $27(19-34)$ \\
Other* & 11 & $17(12-30)$ \\
Total & 181 & $31(21-38)$ \\
\hline
\end{tabular}

${ }^{1}$ Double entries are possible because a worker may have been employed in a number of activities consecutively.

${ }^{2}$ A working time of zero (i.e., an activity which a worker never performed) was not considered for calculation of the median.

Other explanations and abbreviations as in Table 1.

really always related to the disease, our results must be considered as a rough estimation only.

The effective working time or exposure time in an activity is shorter than the difference between the year of recognition and the year of starting work. We estimated the effective working time with the help of the working histories in the insurance dossiers (Table 3). The median calculated working time was 31 years $(\mathrm{IQR}=21-$ 38 years), whereby the real working times were lower because we inserted an employment rate of $100 \%$ whenever there was no information on the employment rate in the working history. The median calculated working time in Switzerland (21 years; IQR $=10-33$ years) was obviously longer than the working time outside of Switzerland (15 years; IQR = 9-23 years).

\section{Influence of smoking}

Smoking history was recorded in the insurance files of 155 workers, out of whom $115(75 \%)$ workers were ever-smokers and 40 were never-smokers $(25 \%)$. The
Table 4. Pack years of various groups of workers in studied enterprises in Switzerland, 2005-2014

\begin{tabular}{lcl}
\hline \multicolumn{1}{c}{ Workers } & $\begin{array}{c}\text { Workers } \\
{[\mathrm{n}]}\end{array}$ & $\begin{array}{l}\text { Pack years* } \\
\text { (Me (IQR)) }\end{array}$ \\
\hline With recorded pack years & 133 & $15(0-30)$ \\
Ever-smoker & 94 & $20(15-40)$ \\
With cancer & 6 & $40(30-80)$ \\
Without cancer & 127 & $15(0-30)$ \\
With COPD & 38 & $25(15-40)$ \\
Without COPD & 95 & $14(0-23)$ \\
\hline
\end{tabular}

COPD - chronic obstructive pulmonary disease.

Abbreviations as in Table 1.

* The number of pack years of those workers with lung cancer or COPD is significantly higher than the pack years of the workers without disease $(p<0.05)$.

smoking status at the time point of registration of silicosis is known for 160 workers, out of whom 47 (29\%) workers were currently smoking. The number of pack years was described in the dossiers of 133 workers (Table 4): the median number of pack years of all these 133 workers was 15 whereas the median number of pack years of the ever-smokers $(\mathrm{N}=94)$ was 20.

All workers with lung cancer $(\mathrm{N}=8 / 8)$ and $84 \%$ of the workers with COPD $(\mathrm{N}=51 / 55)$ were ever-smokers. The median number of pack years of workers with and without lung cancer and/or COPD is summarized in the Table 4. All workers with lung cancer were ever-smokers, and their number of pack years was significantly higher (median of 40 pack years) than the number of pack years of the workers without lung cancer (median of 15 pack years). The number of pack years of the workers with COPD was significantly higher (median of 25 pack years) than the number of pack years of the workers without COPD (median of 14 pack years).

\section{Acquisition of silicosis in and outside of Switzerland}

There were 84 foreign workers who started their work outside of Switzerland (63\% of 133 foreign workers). 
The extent to which these workers acquired silicosis in and outside of Switzerland remains unknown. As it takes 10-20 years of exposure to produce silicosis [2] and as silicosis progresses even when there is no longer additional exposure, the disease could have its origin before immigration and could have manifested clinically in Switzerland. We determined the number of workers who had worked more than 10 or 20 years abroad before immigration. Therefore, we analyzed those 69 foreigners who never returned to their home country after having entered Switzerland. Their median working time outside of Switzerland was 13 years (IQR = 6-21 years). Out of these 69 workers, $41(60 \%)$ and 19 (28\%) had worked more than 10 and 20 years abroad, respectively, and could therefore have completely acquired silicosis abroad. The workers came from Portugal $(\mathrm{N}=35$; $66 \%$ of all 53 Portuguese), Italy ( $\mathrm{N}=19 ; 46 \%$ of all 41 Italians), Austria ( $\mathrm{N}=7 ; 78 \%$ of all 9 Austrians) and other countries $(\mathrm{N}=8)$. They had worked in stone processing $(\mathrm{N}=52)$, tunneling $(\mathrm{N}=19)$, construction $(\mathrm{N}=9)$, foundries $(\mathrm{N}=2)$ and ceramics $(\mathrm{N}=1)$ (double entries are possible) before immigration.

Moreover, we compared the quartz years and the working times outside and inside of Switzerland. There were 22 foreign workers for whom Suva occupational hygienists determined the silica burden both for their occupation in and outside of Switzerland. The median quartz years acquired in Switzerland was $2.1 \mathrm{mg} / \mathrm{m}^{3} \times y$ (IQR $=1.1-$ $4.3 \mathrm{mg} / \mathrm{m}^{3} \times \mathrm{y}$ ), and the median quartz years acquired abroad was $3 \mathrm{mg} / \mathrm{m}^{3} \times y$ (IQR $\left.=1.0-8.6 \mathrm{mg} / \mathrm{m}^{3} \times y\right)$. There was no significant difference between the quartz years per worker acquired in Switzerland (41\% of the total quartz years) and the quartz years per worker accumulated outside of Switzerland (59\% of the total quartz years). There was also no significant difference in working times outside and inside Switzerland among those 84 foreigners who began to work outside of Switzerland. The median working time outside and inside of Switzerland was 14 years, with an IQR = 8-23 years and 6-24 years, respectively. For the calculation, we assumed that all conditions, such as quartz dust concentrations and daily working hours, were the same in all locations. In cases for which there was no information on the employment rate, the value of $100 \%$ was adopted.

\section{DISCUSSION}

This study shows that the incidence of silicosis has drastically decreased from over 300 cases/year at approximately 1970 to below 20 cases/year in the nineties. Nonetheless, silicosis has not disappeared, and quartz dust concentrations in workplaces are still often above the current Swiss OEL.

\section{Silica dust concentrations}

Measurements of workplace quartz dust air-monitoring campaigns have mainly been performed for stone processing and tunneling, to a lesser extent for gravel quarries and foundries, and very rarely for the ceramic industry and other unspecified activities. The median concentration of all measurements and of the measurements in stone processing, tunneling, foundries and ceramics ranged $0.08-0.09 \mathrm{mg} / \mathrm{m}^{3}$ (a), i.e., below the Swiss OEL of $0.15 \mathrm{mg} / \mathrm{m}^{3}$ (a) (Table 1 ).

The median silica dust level was nearly twice as high in gravel quarries as in the other activities because Suva frequently performed occupational health surveillance measurements in areas of gravel quarries where the highest exposures are expected. However, workers generally do not remain in these areas for longer times, and thus these measurements are of minor relevance to workers' health and are not further discussed in this chapter.

Hardly any measurements have been collected at construction sites (they are listed under "other activities"), which is surprising because every seventh quartz dust-induced disease originates from an occupation in the construction sector $[17,18]$. The explanation for this observation resides 
in the constant changes in construction places and activities and often poor representative nature of measurements over a longer time period.

Among all measurements, 28\% were above the Swiss OEL for alveolar crystalline silica of $0.15 \mathrm{mg} / \mathrm{m}^{3}$ (Table 2). This value may be higher than expected in a typical company because Suva often acquires measurements when bad working conditions are suspected or have been observed during an earlier plant visit. Conversely, we assume that the proportion of higher quartz dust concentrations was higher in previous decades than at present. When a lower OEL of $0.1 \mathrm{mg} / \mathrm{m}^{3}$ or even $0.05 \mathrm{mg} / \mathrm{m}^{3}$ (a) is applied to determine the percentage of quartz dust levels that are too high, $43 \%$ or even $68 \%$ of all measurements would be above the limit, respectively (Table 2).

\section{Incidence of silicosis}

In Switzerland, the incidence of silicosis was highest between the 1940s and 1970s, possibly due to the wide-spread underground construction works during the World Wars and Cold War period, such as the military "réduit" [19]; moreover, dust-reducing protective measures were absent or lacked efficacy. A half of the workers in our study started to work before 1972 (Figure 1), which is only one year after the former OEL of $0.3 \mathrm{mg} / \mathrm{m}^{3}$ (a) had been introduced in Switzerland.

In the 1970s, the incidence of silicosis declined from a maximum of 318 cases/year during the 5-year period 1968-1972 to below 20 cases/year during the 5-year period from 1998-2002 (Figure 5) [20]. Since then, the incidence has been more or less stable. In our study, which covers the years between 2005 and 2014, Suva acknowledged 19 cases/year (median). Out of these, 2 workers per year died due to quartz dust-related silicosis or lung cancer (when the influence of smoking is not considered, see below). More than a half of the concerned workers with silicosis were occupied in stone processing and every fourth worked in tunnels. The incidence of silicosis might be higher than the incidence reported in this paper because not all silicosis detected by a physician might have been linked to a working place due to the very long latency time between exposure and diagnosis.
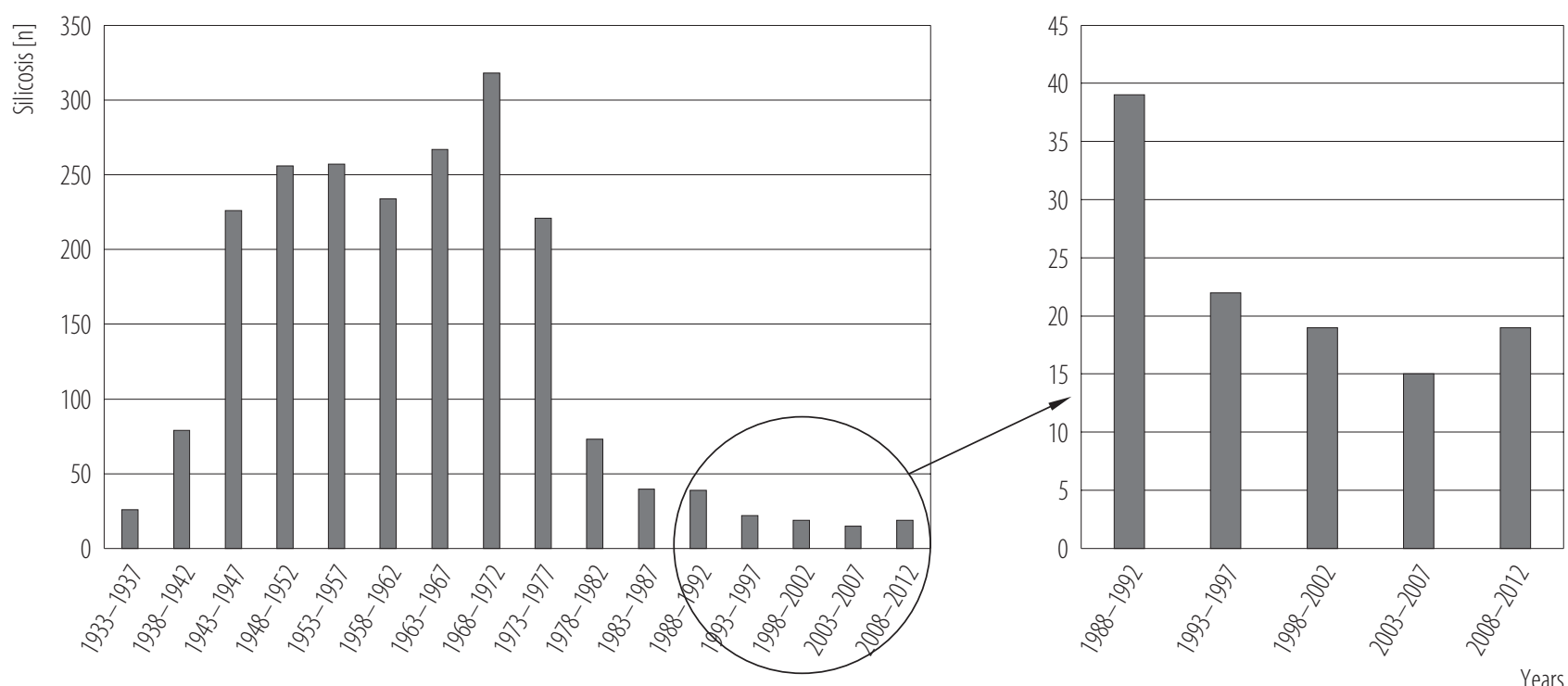

SSUV - Swiss Central Office for Statistics in Accident Insurance (Sammelstelle für die Statistik der Unfallversicherung).

Fig. 5. Incidence of silicosis (mean of 5 years) according to the 5-year reports of the accident statistics of SSUV, Switzerland, 1933-2012 
In Switzerland, the incidence of silicosis is in the same range as that of respiratory diseases due to isocyanates and other dusts, but it is clearly lower than that of lung diseases due to asbestos (approximately 150 cases/year) and flour dust (approximately 60 cases/year) [21]. The incidence conforms to approximately $5 \%$ of all occupational respiratory diseases and to $<1 \%$ of all occupational diseases per year.

The decreased incidence of silicosis started when the current Swiss OEL was implemented in 1975. Since the exposure time of 10-20 years is needed for the development of silicosis [2], the introduction of the Swiss OEL may only partially explain the decline in incidence. Surprisingly, 20 years after the implementation of the Swiss OEL, there was no further decline, and the incidence remained stable. The same behavior concerning the incidence of silicosis was observed in the USA after implementation of the permissible exposure limit (PEL) for crystalline silica in 1971 [6]. Neither we nor the Occupational Safety and Health Administration (OSHA) has an explanation for the decreased incidence of silicosis in the 1970s and the stabilization 20 years later [6]. Further analysis of the data for that and previous times would be necessary to elucidate the cause of this phenomenon.

Some possible explanations for the decline beginning in the 1970s include the following:

- improvement of working conditions and protection measures in the fifties, which may have influenced the incidence of silicosis 20 years later,

- employment of fewer workers at large construction sites in the Alps in the fifties, which also may have influenced the frequency of silicosis 20 years later,

- more accurate diagnostic possibilities (we estimate that up $30 \%$ of silicosis cases could be incorrectly diagnosed when only chest X-ray are performed [22]).

Some reasons for stabilization of the incidence of silicosis in the early nineties could include the following:

- a high background prevalence (11\%) of small lung opacities in the European population that is not ex- posed to dust in radiography, which may be mistaken as silicosis when no further diagnostic measures are applied [23],

- a half of the workers started to work before implementation of the new Swiss OEL,

- the extraordinary long latency time (approximately 40 years) between the start of work and recognition of disease,

- the ongoing immigration of workers who had already been exposed to high silica concentrations in their home countries.

It is not possible to calculate the relative risk of acquiring silicosis based on our data for the following reasons. First, the data for silica exposure is only available at the aggregated level or as isolated sample measurements. Second, there is a long latency and long-term accumulation of silica doses, making it difficult to assign a proximate cause. Finally, too little is known about the reference group, i.e., the workers who had been exposed to silica but did not develop silicosis. Here, a healthy worker survivor effect or that individuals with early symptoms of silicosis are no longer exposed and thus are not detected in epidemiologic studies must be considered.

\section{Severity of silicosis}

The respiratory symptoms do not necessarily correspond to the changes observed on radiography [22]. Therefore, it is not possible to consider the ILO graduation of the chest X-rays as a surrogate for the severity of silicosis.

Additionally, other symptoms, such as coughing and dyspnea that are mentioned in the medical dossiers cannot be considered as surrogates because they are not specific, inconsistent over time and sometimes subjective.

As hints for the degree of severity, we considered the spirometric parameters $\mathrm{FEV}_{1}$ and $\mathrm{FVC}$, the percentage share of declarations of unsuitability and the percentage share of silicosis occasionally detected during routine occupational medical prophylaxis investigations. 
The impairment of lung function during the medical exams was moderate: the median $\mathrm{FEV}_{1}$, the median FVC and the median/mean $\mathrm{FEV}_{1} / \mathrm{FVC}$ ratio were $86 \%$, 92\% and 0.78 , respectively. The median $\mathrm{FEV}_{1} / \mathrm{FVC}$ ratio is above the limit for COPD of 0.7 according to Global Initiative for Chronic Obstructive Lung Disease (GOLD) [24] and corresponds to the mean ratio of 0.79 (males, 55 years, $175 \mathrm{~cm}$ ) published in a recent analysis of nearly 100000 healthy individuals [25].

In this study, $27 \%$ of the workers (17 of 64) qualified for a COPD diagnosis according to GOLD (stage $\mathrm{I}=6$, stage II $=8$, stage III $=3$ ), which is in the same range as the percentage $(30 \%)$ recorded in the medical dossiers and, e.g., in the German and Austrian participants of the Burden of Obstructive Lung Disease (BOLD) study, where $18 \%$ and $27 \%$ of the male population (mean age of 58 years old) in Germany and Austria, respectively, displayed COPD stage I-IV [26]. However, the spirometric data collected from the medical files must be considered as estimations of lung function only because prebronchodilator values were provided (whereas GOLD is based on post-bronchodilator values). We analyzed these values because often no bronchodilation has been performed during the medical examination. Conversely, we assumed that patients who used bronchodilators on a regular basis often did not stop their medication on the day the spirometry was performed because there no instructions were provided to physicians regarding this issue.

Although there is evidence that quartz dust may cause COPD, the main cause of this disease is most likely smoking.

Among persons affected by silica-related occupational diseases, $14 \%$ received a declaration of unsuitability for work in dust-burdened environments. This rate is in the range of occupational diseases in general during recent years (12\% on average; internal data from Suva). However, we found that there were more workers who did not continue with their activity, the exact number being unknown due to lacking follow-up. The reasons for no additional declarations may be mildness of the symptoms (i.e., an only moderate decrease in airflow parameters at the time point of recognition), proviso permissions to continue to work (i.e., if a breathing mask is worn or if technical protective measures are installed), the retired status of a worker at the time silicosis was acknowledged (the median age at the time of recognition was 58 years old), or a change in activity by the workers themselves before the disease was recognized by Suva.

Most cases of silicosis were not identified during a regular physician visit but during a routine occupational medical prophylaxis investigation (79 out of 153 known cases). In these cases, symptoms were either lacking or were too weak to lead to a doctor's visit. This finding challenges the assumption that the health surveillance programs currently used in Switzerland are effective for detecting early silicosis.

Altogether, silicosis often did not impair a worker substantially at the time point of recognition. However, as silicosis progresses - even in those cases where exposure stops, the disease becomes increasingly severe and can sometimes lead to death. Out of those cases that had been acknowledged between 2005 and 2014, there were 2 deaths/year due to silicosis and lung cancer until 2014. The total number of deaths will certainly increase over time.

\section{Influence of smoking}

Smoking was common among the investigated workers. Three quarters of the workers were ever-smokers. Some quartz dust-induced respiratory diseases, such as COPD or lung cancer, may also be evoked by tobacco smoke. Moreover, smoking enhances the risk of developing silicosis during exposure to silica dust [12]. Therefore, it is important to consider both quartz dust exposure and smoking history when determining the causation of a respiratory disease. The most common secondary diagnosis concerning the lung was COPD, which was present for $27 \%$ of all work- 
ers when taking their $\mathrm{FEV}_{1} / \mathrm{FVC}$ ratios into account and applying the GOLD definition for COPD. It is well known that tobacco smoke is the most common cause of COPD. Therefore, it is not astonishing that the workers with COPD in our study most often were ever-smokers (85\%), with a median of 25 pack years - in contrast, workers without COPD had only 14 pack years $(\mathrm{p}<0.01$; Table 4). For smokers with 25 pack years, the risk of developing COPD is approximately double that for non-smokers [27]. Other studies further report a decrease in $\mathrm{FEV}_{1}$ values and $\mathrm{FEV}_{1} / \mathrm{FVC}$ ratios in workers exposed to quartz dust [26]; however, the dose-response relationship is less well consolidated compared with that for tobacco smoke. As it is not possible to determine the extent to which smoking or silica dust is responsible for COPD, physicians usually do not comment on the causality of COPD in insurance files.

Lung cancer was the second most important secondary diagnosis concerning the respiratory tract. Lung cancer was diagnosed in 8 workers and acknowledged as related to silica dust by Suva due to the presence of silicosis with an ILO grade of at least $1 / 1$. Five of these workers died due to cancer up to 2014. All workers with lung cancer were ever-smokers - as observed in other studies [28]. The median pack years was 40 - in contrast, workers without lung cancer had a significantly lower burden of only 15 pack years (Table 4). Smokers with 40 pack years had a 2-4 times higher risk of developing lung cancer than smokers with 15 pack years, depending on the duration and the intensity $[29,30]$. The probability of developing lung cancer for smokers with 40 pack years and 15 pack years is - roughly estimated - at most 30 and 10 times higher than those for non-smokers, respectively [31]. In contrast, the standardized mortality and incidence ratios of lung cancer due to exposure to silica dust are less than 2 according to a recent meta-analysis [32]. The presence of silicosis seems to increase the risk of developing lung cancer [32].
Altogether, it seems that an unknown portion of lung cancers are caused by smoking rather than exposure to silica dust. The incidence of acknowledged quartz dust-induced lung cancer is therefore probably overestimated. Regardless, the high prevalence of smokers urges the implementation of preventive anti-smoking measures in the work place.

\section{Acquisition of silica outside of Switzerland}

The majority of workers $(73 \%)$ were born in countries other than Switzerland. The 3 most common foreign countries were Portugal (29\%), Italy (23\%) and Austria (5\%). Most Italian workers in our study population began to work after approximately 1945 whereas the Portuguese workers were approximately 15 years younger and started working after approximately 1960 (Figures 1 and 2). Therefore, the Italian were older than the Portuguese workers at the time of acknowledgement of silicosis, and therefore the working duration until recognition of the disease was longer for the Italians than for the Portuguese. The workers were sometimes very young when they started their occupation in a silica-exposed activity: 28 workers from Italy and Portugal were younger than 15 years old, with the youngest being 10 years old.

Two thirds of the foreign workers had been working abroad $(\mathrm{Me}=13$ years $)$ before coming to Switzerland. If we assume that 10-20 years of exposure are needed to develop quartz dust-related silicosis [2], then $28 \%$ and $60 \%$ of these workers would have been working long enough abroad to acquire silicosis outside of Switzerland (the percentages are lower in reality because we considered an employment rate of $100 \%$ when the rate was not provided in the medical dossier). After immigration, an "imported" silicosis progresses and is finally detected by a medical doctor. This process normally takes a long time because it lasted about 40 years (median) after starting work until silicosis was acknowledged. At the time point of acknowledgement, the workers were 58 years old (median) - which is not far from the age of retirement. It is noteworthy that 
the real exposure time was shorter than 40 years, which is explained as follows: The effective exposure time in an activity is shorter than the difference between the year of recognition and the year of starting work because the workers were not consistently employed in an occupation with silica dust exposure. Moreover, the employment rate and the number of working hours per day were not always exactly described in the insurance dossiers (which is of importance in the case of seasonal workers). Since silicosis progresses even after no further exposure, the workers may have already been retired when their silicosis was acknowledged as an occupational disease.

Another way to estimate the extent to which exposure outside of Switzerland contributed to the development of silicosis is either by comparing the quartz dust accumulation or the working time inside and outside of Switzerland. We found that the acquired silica dust and working time inside and outside of Switzerland were approximately equal; however, this is a rough estimation only because the calculation of quartz years is insecure and because the quartz years are only based on the data collected from 22 workers in this study. Moreover, we assumed that the working conditions and silica concentrations were similar everywhere. Additionally, one must keep in mind that silicosis progresses even after no further exposure in Switzerland. Altogether, we found that the workers who had started working abroad may have acquired an essential portion of the silica dust burden outside of Switzerland.

\section{Study limitations}

This study is the analysis of various databases and medical dossiers. Therefore, the data was often heterogeneous, incomplete, inconsistent over time or not representative. The medical doctors did not follow a defined algorithm when they diagnosed silicosis, when they clarified the causality of silicosis, and when they wrote down the working history, among others. We have not formally assessed the quality of the spirometries performed by the physicians, or whether they were performed according to criteria published by e.g., the American Thoracic Society [33]. Prior research had shown that spirometries performed by general practitioners in Switzerland had met acceptable quality in approximately $60 \%$ of measurements [34]. Unlike in other countries such as, e.g., the USA, medical doctors in Switzerland do not have to be qualified when interpreting X-rays of workers at risk for pneumoconiosis in statutory health surveillance programs. Thus, variability in reporting X-rays findings has been shown to occur, which could be reduced by standardized teaching and recertification of physicians [35].

We were neither able to derive a quantitative dose-response relationship or a relative rate of developing silicosis. Due to the design of this study, the follow-up time for outcome variables was longer for cases registered at the beginning and much shorter for cases registered at the end of the study period. For a disease with long-term effects, such as silicosis, the follow-up may have been too short to evaluate all consequences. In particular, we cannot provide results for the long-term mortality of the silicosis patients. In many cases, we are unable to provide exact calculations but only rough estimations. However, such an analysis mirrors the reality of practice. Due to the limited time period examined, not all observations may be explained. Further analysis is therefore recommended.

\section{CONCLUSIONS}

In this study, we have analyzed alveolar crystalline silica dust concentrations measured by Suva and the number of cases of silicosis acknowledged by Suva between 2005 and 2014. We have observed that the incidence of silicosis dramatically decreased from approximately 1970 with over 300 cases/year to below 20 cases/year approximately 20 years ago. Silicosis now represents approximately $5 \%$ of all occupational diseases of the respiratory tract per year in Switzerland, which is less than $1 \%$ of all occupational diseases [21]. 
Our study shows that - at least in part - cases of silicosis in Switzerland could be due to the following:

- Every fourth measured alveolar quartz dust concentration was above the Swiss OEL of $0.15 \mathrm{mg} / \mathrm{m}^{3}$.

- Every second worker began to work before 1975, which is the year when the Swiss OEL for crystalline silica was lowered to the current value.

- The average time between the start of work and recognition of silicosis was very long - it was 40 years in this study. However, this did not indicate 40 years of exposure because the workers were not consistently exposed during their working life and silicosis progresses even after no further (dangerous) exposure to quartz dust (e.g., after retirement).

- Three quarters of the workers were foreigners, out of whom two thirds had worked abroad before immigrating into Switzerland with a median working time of 13 years. Every fourth up to more than a half of these workers were exposed to silica dust sufficiently long abroad (theoretically) to acquire silicosis outside of Switzerland.

- Personal protective equipment was often not always carried adequately.

- Three quarters of the workers were ever-smokers. Smoking facilitates the development of silicosis and lung cancer. This study shows that a portion of the lung cancers may be preferably ascribed to tobacco smoking than to exposure to quartz dust.

- The background level of small lung opacities $($ ILO $\geq 0 / 1)$ in the case of European men who were not exposed to dust is $11 \%$. Therefore, a portion of the cases of silicosis with a diagnosis based on chest $\mathrm{X}$-ray may have been false positively diagnosed. Thus, basing a diagnosis of silicosis on X-ray only should be avoided.

- There is no information about silica dust concentrations in construction activities. The levels may have been quite high because every 7 th case of silicosis was correlated with an activity in the construction sector. Thus, additional measurements are recommended.

- Evaluation of the adequacy of the Swiss OEL was not the aim of this study, and this should be assessed in further investigations.

The severity of symptoms at the time point of recognition was moderate in general - however, silicosis worsens over time and even can lead to death (as was noted in one to 2 cases/year in this study). At the time point of recognition:

1. $\mathrm{FEV}_{1}$ (median, pre-bronchodilator values) was only about $15 \%$ lower than the normal values, which could also be due to smoking.

2. The percentage share of workers who received a declaration of unsuitability by Suva (14\%) was in the range of other occupational diseases.

3. Every second silicosis was diagnosed in a routine medical prophylaxis investigation; these workers did not visit a medical doctor because of symptoms, supporting the importance of current health surveillance programs in Switzerland.

\section{REFERENCES}

1. Leung CC, Yu IT, Chen W. Silicosis. Lancet. 2012;379(9830): 2008-18, https://doi.org/10.1016/S0140-6736(12)60235-9.

2. Cullinan P, Reid P. Pneumoconiosis. Prim Care Resp J. 2013;22(2):249-52, https://doi.org/10.4104/pcrj.2013.00055.

3. International Labour Office (ILO). Guidelines for the use of the ILO international classification of radiographs of pneumoconiosis. Geneva: The Office; 2002.

4. Suva. [Occupational exposure limits 2016]. Luzern: Suva; 2016. German.

5. International Agency for Research on Cancer (IARC). Silica dust, crystalline, in the form of quarz or cristobalite. Arsenic, metals, fibers and dusts. Lyon: The Agency; 2012. p. 355-405.

6. Occupational Safety and Health Administration (OSHA). Occupational exposure to respirable crystalline silica. Washington: The Administration; 2016. 
7. Borm PJ, Tran L, Donaldson K. The carcinogenic action of crystalline silica: A review of the evidence supporting secondary inflammation-driven genotoxicity as a principal mechanism. Crit Rev Toxicol. 2011;41(9):756-70, https://doi. org/10.3109/10408444.2011.576008.

8. Morfeld P. Exposure-response association between cumulative exposure to respirable crystalline silica dust and lung cancer. Zbl Arbeitsmed Arbeitsschutz Ergon. 2013;63(4):190-200.

9. Steenland K, Mannetje A, Boffetta P, Stayner L, Attfield $\mathrm{M}$, Chen J, et al. Pooled exposure-response analyses and risk assessment for lung cancer in 10 cohorts of silica-exposed workers: An IARC multicentre study. Cancer Causes Control. 2001;12(9):773-84, https://doi. org/10.1023/A:1012214102061.

10. Sogl M, Taeger D, Pallapies D, Bruning T, Dufey F, Schnelzer M, et al. Quantitative relationship between silica exposure and lung cancer mortality in German uranium miners, 1946-2003. Brit J Cancer. 2012;107(7):1188-94, https://doi. org/10.1038/bjc. 2012.374 .

11. Ausschuss für Gefahrstoffe (AGS). [Argumentation for occupational exposure limit of quartz]. Berlin: Bundesanstalt für Arbeitsschutz und Arbeitsmedizin (BAuA); 2015. German.

12. Brown T. Silica exposure, smoking, silicosis and lung cancer - Complex interactions. Occup Med (Lond). 2009;59(2): 89-95, https://doi.org/10.1093/occmed/kqn171.

13. Health and Safety Executive (HSE). Respirable crystalline silica - Phase 2. Hazard assessment document. London: HSE Books; 2003.

14. Möhner M, Kersten N, Gellissen J. Chronic obstructive pulmonary disease and longitudinal changes in pulmonary function due to occupational exposure to respirable quartz. Occup Environ Med. 2013;70(1):9-14, https://doi.org/ 10.1136/oemed-2012-100775.

15. Brüske I, Thiering E, Heinrich J, Huster KM, Nowak D. Respirable quartz dust exposure and airway obstruction: A systematic review and meta-analysis. Occup
Environ Med. 2014;71(8):583-9, https://doi.org/10.1136/oe med-2013-101796.

16. Bundesministerium für Arbeit und Soziales (BMAS). [Chronic obstructive airway disease (COPD) by inhalation of inorganic dust at the workplace. Systematic review of epidemiological studies and meta-analysis]. Berlin: Bundesministerium; 2012. German.

17. Tjoe Nij E, Burdorf A, Parker J, Attfield M, van Duivenbooden C, Heederik D. Radiographic abnormalities among construction workers exposed to quartz containing dust. Occup Environ Med. 2003;60(6):410-7, https://doi.org/10. 1136/oem.60.6.410.

18. Suarthana E, Moons KG, Heederik D, Meijer E. A simple diagnostic model for ruling out pneumoconiosis among construction workers. Occup Environ Med. 2007;64(9):595-601, https://doi.org/10.1136/oem.2006.027904.

19. Lengwiler M. [Technologies of trust]. Neue Zürcher Zeitung. 16.01.2001. German.

20. Statistik der Unfallersicherung UVG [Internet]. Luzern: SSUV; 2017 [cited 2017 April 27]. Available from: http:// www.unfallstatistik.ch.

21. Suva. [Accident statistics 2015]. Luzern: Suva; 2016. German. 22. Baur M, Heger M, Bohle R, Hering K, Hofmann-Preiss K, Nowak D, et al. [Diagnosis and assessment of occupational disease Nr. 4101 silicosis of the occupational disease regulation.] Arbeitsmed Sozialmed Umweltmed. 2014;(51):86897. German.

23. Meyer JD, Islam SS, Ducatman AM, McCunney RJ. Prevalence of small lung opacities in populations unexposed to dusts. A literature analysis. Chest. 1997;111(2):404-10, https://doi.org/10.1378/chest.111.2.404.

24. Global Initiative for Chronic Obstructive Lung Disease. Pocket guide to COPD diagnosis, management, and prevention. A guide for health care professionals. The Initiative; 2017.

25. Quanjer PH, Stanojevic S, Cole TJ, Baur X, Hall GL, Culver $\mathrm{BH}$, et al. Multi-ethnic reference values for spirometry for the 3-95-yr age range: The global lung function 2012 
equations. Eur Respir J. 2012;40(6):1324-43, https://doi. org/10.1183/09031936.00080312.

26. Buist AS, McBurnie MA, Vollmer WM, Gillespie S, Burney $\mathrm{P}$, Mannino DM, et al. International variation in the prevalence of COPD (the BOLD Study): A populationbased prevalence study. Lancet. 2007;370(9589):741-50, https://doi.org/10.1016/S0140-6736(07)61377-4.

27. Forey BA, Thornton AJ, Lee PN. Systematic review with meta-analysis of the epidemiological evidence relating smoking to COPD, chronic bronchitis and emphysema. BMC Pulm Med. 2011;11:36, https://doi.org/10.1186/1471-2466-11-36.

28. Graham WG, Costello J, Vacek PM. Vermont granite mortality study: An update with an emphasis on lung cancer. J Occup Environ Med. 2004;46(5):459-66, https://doi. org/10.1097/01.jom.0000126026.22470.6d.

29. Peto J. That the effects of smoking should be measured in pack-years: Misconceptions 4. Br J Cancer. 2012;107(3): 406-7, https://doi.org/10.1038/bjc.2012.97.

30. Lubin JH, Alavanja MC, Caporaso N, Brown LM, Brownson RC, Field RW, et al. Cigarette smoking and cancer risk: Modeling total exposure and intensity. Am J Epidemiol. 2007;166(4):479-89, https://doi.org/10.1093/aje/kwm089.
31. Simonato L, Agudo A, Ahrens W, Benhamou E, Benhamou S, Boffetta P, et al. Lung cancer and cigarette smoking in Europe: An update of risk estimates and an assessment of inter-country heterogeneity. Int J Cancer. 2001;91(6):876-87, https://doi.org/10.1002/1097-0215(200102)9999:9999<::AIDIJC1139>3.0.CO;2-7.

32. Poinen-Rughooputh S, Rughooputh MS, Guo Y, Rong Y, Chen W. Occupational exposure to silica dust and risk of lung cancer: An updated meta-analysis of epidemiological studies. BMC Public Health. 2016;16(1):1137, https://doi. org/10.1186/s12889-016-3791-5.

33. American Thoracic Society. Standardization of spirometry, 1994 update. Am J Resp Crit Care. 1995;152(3):1107-36, https://doi.org/10.1164/ajrccm.152.3.7663792.

34. Leuppi JD, Miedinger D, Chhajed PN, Buess C, Schafroth S, Bucher HC, et al. Quality of spirometry in primary care for case finding of airway obstruction in smokers. Respiration. 2010;79(6):469-74, https://doi.org/10.1159/000243162.

35. Felson B, Morgan WK, Bristol LJ, Pendergrass EP, Dessen EL, Linton OW, et al. Observations on the results of multiple readings of chest films in coal miners' pneumoconiosis. Radiology. 1973;109(1):19-23, https://doi.org/10.1148/109.1.19.

This work is available in Open Access model and licensed under a Creative Commons Attribution-NonCommercial 3.0 Poland License - http://creativecommons.org/ licenses/by-nc/3.0/pl/deed.en. 